\title{
Article
}

\section{Complexity of Clinical Decision Making: Consent, Capacity, and Ethics}

\author{
Askren, Annette and Leslie, Paula \\ Available at http://clok.uclan.ac.uk/28770/ \\ Askren, Annette and Leslie, Paula ORCID: 0000-0002-0379-9044 (2019) \\ Complexity of Clinical Decision Making: Consent, Capacity, and Ethics. \\ Seminars in Speech and Language, 40 (03). pp. 162-169. ISSN 0734-0478
}

It is advisable to refer to the publisher's version if you intend to cite from the work. http://dx.doi.org/10.1055/s-0039-1688838

For more information about UCLan's research in this area go to

http://www.uclan.ac.uk/researchgroups/ and search for <name of research Group>.

For information about Research generally at UCLan please go to http://www.uclan.ac.uk/research/

All outputs in CLoK are protected by Intellectual Property Rights law, including Copyright law. Copyright, IPR and Moral Rights for the works on this site are retained by the individual authors and/or other copyright owners. Terms and conditions for use of this material are defined in the policies page.

\section{CLoK}

Central Lancashire online Knowledge www.clok.uclan.ac.uk

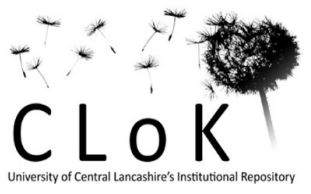




\title{
Complexity of Clinical Decision Making: Consent, Capacity, and Ethics
}

\author{
Annette Askren, CScD, CCC-SLP \\ Speech-Language Pathologist \\ VA Pittsburgh Healthcare System \\ Adjunct Professor, West Virginia University \\ annette.askren@va.gov \\ University Drive C, 112-SpU \\ Pittsburgh, PA 15240 \\ 412-360-3465
}

Paula Leslie PhD, MA Bioethics

Senior Lecturer Speech \& Language Therapy

FRCSLT, CCC-SLP

School of Health Sciences

University of Central Lancashire

Preston

PR1 2HE

United Kingdom

TBC after May $1^{\text {st }}:$ e-mail address, and telephone and fax numbers 


\section{Abstract}

Speech-language pathologists (SLPs), and really their patients, are often faced with challenging clinical decisions to be made. Patients may decline interventions recommended by the SLP and are often inappropriately labeled "non compliant." The inappropriateness of this label extends beyond the negative charge; the patient's right to refuse is, in fact, protected by law. Anecdotal exchanges, social media platforms, and ASHA forums have recently revealed that many SLPs are struggling with the patient right to decline. Many are not comfortable with the informed consent process and what entails patients' capacity to make their own medical decisions. Here, we discuss the basics of clinical decision-making ethics with intent to minimize the clinician's discomfort with the right to refuse those thickened liquids and eliminate the practice of defensive medicine.

\section{Key Words}

Ethics, consent, capacity, decision-making

\section{Learner Outcomes}

1) The learner will be able to compare and contrast competency and capacity as it applies to an individual's ability to make medical decisions.

2) The learner will be able to reference five, hallmark Court cases that led to the current state of a patient's autonomous right to make medical decisions.

3) The learner will be able to list and define four components of patient decision-making capacity. 
4) The learner will be able to describe the informed consent process and list four key requirements.

\section{Introduction}

Since the early 1970s the speech-language pathologist (SLP) has engaged in the assessment, management, and treatment of individuals with dysphagia. ${ }^{1}$ It was not until the late $1980 \mathrm{~s}$, however, that our role in this population was recognized by the leading health organizations accrediting our facilities: The Joint Commission, The National Center for Health Services Research and Healthcare Technology Assessment. Since that time, swallowing and swallowing disorders have become major areas of our field, now a requirement within the graduate-level curriculum (see the American Speech-Language-Hearing Association's Technical Report, 2007). According to the American Speech-Language-Hearing Association (ASHA), the 2017 Healthcare Survey reported that over $50 \%$ of an SLP's caseload within an acute care setting included individuals with dysphagia. ${ }^{2}$ This area is no longer just encountered by the medical SLP. ASHA's most recent Schools Survey (2018) indicated $14.5 \%$ of an elementary- and secondary-school SLP's caseload included children with dysphagia. ${ }^{3}$ An increasingly large percentage of our caseloads include the management of swallowing despite this being a relatively recent development in our field.

A large number of SLPs are engaged with patients experiencing dysphagia, but many still feel uncomfortable with the informed consent process and (likely more so) the refusal of our recommendations by the patient or family member. In fact, many SLPs do not even acknowledge these areas as aspects innate to clinical practice. This resource was developed based on the very 
recent needs demonstrated by our colleagues within electronic exchanges (e.g., social media, email Listserv). You will find quotes that lead into each section and reflect, anonymously, the difficult clinical dilemmas we are facing as a field.

Decision making: what's the big deal?

Patients who decline to participate in an SLP's recommendations are often labeled "noncompliant" or "non-adherent." Colodny reported that $40 \%$ of a sample of 190 residents in a nursing home were deemed "not compliant" with the recommendations for oral diet modification made by an SLP. ${ }^{4}$ These figures support the significant sense of conflict many of our colleagues feel while working with this population. A leading source for patients" "non compliance" is a poor understanding of one's condition. ${ }^{5}$ Patients often choose not to engage in a treatment recommendation because they do not understand the rationale. The following primer works to reverse our roles as patient (or learner) and clinician expert (or educator). Perhaps our discomfort and distance from this topic is related to our own poor understanding of clinical decisionmaking. Hopefully, by clarifying this area and better educating the field, we, too, will comply with our ethical obligation to partake in the informed consent and decision-making processes of our patients.

While it is not the intent of this piece to provide an exhaustive review of the ethical frameworks for our practices, select pearls always deserve revisiting. Three important concepts guide the practice of medicine: we serve to promote the welfare of our patients, we serve to acknowledge and uphold our patient's autonomous decisions regarding their medical care, and a patient's right 
to self-determination will always trump our interests in promoting our view of a patient's well being. ${ }^{6}$

\section{ASHA Fundamentals}

SLP Inquiry: "I think this has been touched on in the past, but does anyone have research or links to ASHA statements, etc. re: our role or scope of practice re: determining competency? (Related to discharge from facility)"

\section{ASHA Code of Ethics: Principle I.H.: ${ }^{7}$}

“...If diminished decision-making ability of persons served is suspected, individuals should seek appropriate authorization for services, such as authorization from a spouse, other family member, or legally authorized/appointed representative."

An individual deemed to be incompetent differs in the legal sense from that of clinical decisionmaking capacity. Competence, or more currently named legal capacity, is a judgment made in a court of law as to a person's requisite functional abilities to make a decision. ${ }^{8,9}$ This more global term applies across a person's spectrum of affairs, including financial management. ${ }^{10}$ A longterm, surrogate decision-maker is appointed in such situations. ${ }^{11}$

In contrast, an individual's clinical capacity to make medical decisions is determined by a clinical provider and reflects a distinct decision to be made at a distinct moment in time. Clinical capacity can be viewed as a dimensional quality, or a point along a continuum, and can appropriately change with time. ${ }^{11}$ 
Four functional abilities were proposed by Grisso \& Appelbaum to explain decision-making capacity after their extensive review of the legal and medical literature. ${ }^{8}$ Collectively, the medical field has adopted these standards as a useful framework for determining one's capacity to make a decision:

1) The ability to express a choice is often first to be addressed and is a universal functional ability acknowledged across the United States. Much to our relief, the medical literature acknowledges this ability need not be verbal. Grisso \& Appelbaum acknowledge that alternative forms of communication may need consideration, where appropriate. ${ }^{8}$ An expressed choice should be relatively consistent and avoid a clinical stalemate due to a mental illness or cognitive disorder.

2) The ability to understand the relevant information - adequately disclosed by the recommending provider - is the only other ability universally recognized across the U.S. To no surprise, a patient's ability to comprehend, retain information, and express whether they have indeed understood the information will vary amongst medical conditions and should not be considered criteria for confirming a poor understanding, i.e., a patient with a stroke may be able to comprehend, retain information, and express their understanding with appropriate modifications.

3) The ability to appreciate the information disclosed reflects two concepts. First, the patient acknowledges that the condition is indeed something from which he or she is suffering. Second, the patient can acknowledge how the condition will affect one's individual self and unique situation. 
4) The ability to reason through the options describes a patient's rational manipulation of the information presented in order to make a decision.

\section{History and Law}

SLP Inquiry: “...everyone mentions the Patient Self Determination Act, and I am in 100\% agreement of patients making decisions for themselves when able. However, my DOR and administrator have scared me into believing if I allow a patient to consume a consistency they are not safe on my license could be in jeopardy. Can someone please provide some guidance so I have a leg to stand on next time this situation presents itself?"

Autonomy and shared decision making as twenty first century innovations belie a history dating back over one hundred years. In the early twentieth century, cases began to appear in US courts questioning the physician's right to perform interventions without express permission - even if there was no ultimate harm to the patient or, as in the case of Mohr v. Williams in 1905, actual benefit. ${ }^{12}$ Mrs. Mohr was having trouble with her right ear and consulted Dr. Williams who discovered a perforated eardrum, a polyp, and that the ossicles were probably diseased. He was unable to make a full examination of the left ear because of a foreign substance in the canal. Mrs. Mohr agreed to have surgery on her right ear. When the patient was unconscious, Dr. Williams made a full examination of both ears and determined that the left was in a worse state than the right. He decided to operate on the left ear, which would be better for the patient; however, she was not consulted because she was unconscious. Mrs. Mohr brought suit against Dr. Williams claiming that he had damaged her hearing and injured her person. Because she had not consented to surgery on her left ear, Dr. Williams's actions were deemed wrongful and unlawful, and 
constituted an assault and battery. ${ }^{12}$ This was the one of the first cases of a court finding on the side of the patient rather than the physician.

A decade later we see a case resulting in a court judgment that many of us are familiar with in concept even if we do not know the origin. In 1914, Schloendorff v. Society of New York Hospital addressed the concept that treating a patient without his or her express permission was an act of battery. ${ }^{13}$ This was based on the principle of trespass and uninvited "touching." Ms. Schloendorff was admitted to hospital and consented to being examined under ether to determine if a diagnosed fibroid tumor was malignant, but she did not consent to its removal. The physician found the tumor to be malignant and removed it, thus disregarding the patient's wishes. Mrs. Schloendorff brought suit and the Court found that the operation to which the plaintiff did not consent was medical battery. Justice Benjamin Cardozo wrote in the Court's opinion:

"Every human being of adult years and sound mind has a right to determine what shall be done with his own body; and a surgeon who performs an operation without his patient's consent commits an assault for which he is liable in damages. This is true except in cases of emergency where the patient is unconscious and where it is necessary to operate before consent can be obtained."13

The idea that a physician had a responsibility to inform a patient of possible consequences of treatment $\underline{\text { before }}$ the patient gave permission was not really clearly voiced in the legal world until the mid-twentieth century with cases such as Salgo v. Leland. ${ }^{14}$ This is when we see the term 
“informed consent" first being used. Mr. Salgo awoke paralyzed after an aortography, having never been informed that such a possibility (although rare) might happen. The Court decided that a failure to disclose risks and alternatives was cause for legal action on its own. ${ }^{14}$ Gradually the principle was established that a physician must gain "informed" consent or face a charge of professional negligence. By the late $20^{\text {th }}$ century most US states had moved to a position that a lack of informed consent was an act of negligence (that is not making appropriate disclosure) rather than of battery.

Thus a "standard of disclosure" came into being as part of reasonable professional practice. This standard was initially a physician based one; that is, physicians only need to disclose that which a reasonable body of their peers would. What exactly this might look like was further challenged in 1972. The Canterbury v. Spence case moved us towards a consideration of what is "material" to the patient, from physician to a patient standard: This requires practitioners to disclose the risks that a reasonable patient would want to know. ${ }^{15}$ The court decision included the following warning:

“... the physician must seek and secure his patient's consent before commencing an operation or other course of treatment. It is also clear that the consent, to be efficacious, must be free from imposition upon the patient. It is the settled rule that therapy not authorized by the patient may amount to a tort - a common law battery - by the physician. And it is evident that it is normally impossible to obtain a consent worthy of the name unless the physician first elucidates the options and the perils for the patient's edification." 15 
The court rejected the idea that a physician was only legally responsible to divulge no more than what other reasonable practitioners would do:

"Respect for the patient's right of self-determination on particular therapy demands a standard set by law for physicians rather than one which physicians may or may not impose upon themselves."

In order to make a decision we need information about how the options might work for us. This move to increase the information disclosed and make it specific to a patient seemed to be wise: That is, we need to be thinking of a standard based on a patient's informational needs to make the decision rather than the paternalist physicians' consideration of what is relevant.

Moving forward we see rare federal level action with the Patient Self-Determination Act of 1990. This Act brought about the requirements for health care agencies receiving Medicare or Medicaid reimbursement to accept that patients may consent to, or refuse, interventions and that advance care plans and power of attorney for health care must be respected. The Act builds upon the common-law right of self-determination as guaranteed by the Fourteenth Amendment of the US Constitution. ${ }^{16}$

Informed Consent

SLP Inquiry: "How are you managing 'informed consent'?" 
Hopefully few, if any, clinicians are proceeding in their practices without providing education to the patient and/or surrogate regarding a pending management or treatment regime. If you as an SLP provided even minimal education and the patient elected to participate in your therapies, you have indeed participated in a consent process. This official-sounding, and sometimes scary concept seems only to be questioned in our world when a patient declines to participate in an SLP's recommendation. It is at this juncture the patient is often labeled "non-compliant" or "non-adherent." An important outcome we as healthcare providers anticipate from the informed consent process is that a patient's decisions regarding treatment will be informed. But, how might we expect our patients to be able to produce such if we have not adequately disclosed the information to them? And, if we adequately disclosed the relevant information needed to express an informed, autonomous decision, can we accurately label a patient "non-compliant" if they chose to refuse?

It is no surprise that confusion arises when we are faced with defining our role in the informed consent process, as it is inherent to the determination of capacity. This should not hinder the process we must engage in as a clinical provider, often specialist, who makes medical recommendations.

\section{ASHA Code of Ethics: Principle I.H.:}

"Individuals shall obtain informed consent from the persons they serve about the nature and possible risks and effects of services provided, technology employed, and products dispensed. This obligation also includes informing persons served about possible effects of not engaging in treatment or not following clinical recommendations..." 
The extent to which a provider must disclose varies by state. Importantly, the notion of informed consent should be thought of as a process. In general, the medical literature ascribes the following four requirements: ${ }^{17}$

1) Material facts include those pieces of information that are considered relevant to a decision. These include approaches to determining a diagnosis, the proposed diagnostic procedure or treatment, alternative options, the risks and benefits of the options, and the medical risks of refusing. The standard to which the facts are disclosed further varies by state. A "reasonable practitioner" standard requires facts be disclosed that a reasonable physician would consider important for a patient's decision; a "prudent patient" standard requires facts be disclosed that a reasonable patient would want to know to be able to make a decision. ${ }^{18}$

2) Provider disclosure requires physicians provide truthful responses to a patient's inquiry regarding the physician's experiences with a procedure. Additionally, a physician must disclose financial conflicts of interest.

3) The personnel to be included during a procedure must be disclosed, e.g., a resident physician or medical intern who will be participating in a patient's care.

4) Additional procedures that would be required in the event of a complication must be disclosed. 


\section{Assessing Capacity}

SLP Inquiry: "Have any of you been asked to do a cognitive [evaluation] solely to determine a person's ability to make informed medical decisions? Do you feel comfortable with that request? What assessments do you use?”

A Reply: "Yes, informed consent is out of our scope of practice. Referral to neuropsych."

There is no standard assessment available for use to determine a patients' legal capacity/competence or clinical capacity to make medical decisions. Structured guidelines have been developed. The MacArthur Competence Assessment Tool-Treatment (MacCAT-T) guides providers through a detailed dialogue with the patient, addressing each of the four functional abilities of decision-making while incorporating the process of informed consent. Importantly, this tool uses the patient's own unique decision to be made, rather than assume a hypothetical situation. An accompanying record form serves as added documentation and allows the user to assign a gross rating for each functional ability $(0,1$, or 2). Grisso, Appelbaum, and Hill-Fotouhi caution against the use of such ratings to reflect, alone, one's clinical capacity and legal competency. Rather, the ratings allow for gross comparisons to normative data, collected while developing this tool. ${ }^{19}$ A similar tool, The Assessment of Capacity for Everyday Decision-Making (ACED), was developed in 2008 to assess capacity in those with mild to moderate cognitive impairment. ${ }^{20} \mathrm{~A}$ short, portable form of this assessment, along with similar ratings to the MacCAT-T are available to the public domain. 
The content of these assessments are innately sensitive. The direction of an individual's medical care could be profoundly altered by its results; however, the nature of these assessments illustrate the complex notion of decision-making abilities. No single factor in one's condition (usually) can suffice to complete such an evaluation. Tools such as the Mini Mental State Exam or the Montreal Cognitive Assessment -both frequently administered by an SLP - are not sufficient to determine one's capacity. The results of such an assessment can contribute to the larger picture.

\section{Language and the Preparation for Challenging Discussions}

SLP Inquiry: "Anyone have a sample 'script' that they use to talk to the families of these advanced dementia patients? Do you have a specific article to give to the family? Also, is there a difference in your discussion if the patient is full code (you'd be surprised how many full code advanced dementia patients I have had on my case)?"

How we, as practitioners, choose to address our patients both with and without the person present can influence our approach to education, counseling, and clinical decision making. In 1992, the American Psychological Association developed guidelines for language when discussing individuals with disabilities in scholarly literature. ${ }^{21}$ Health professions' education quickly took to incorporating the principle of person-first language into curricula. With earlier introduction of the concept, students would set the example as newer generations of providers emerged. Unfortunately, this pattern has not come to light, and disuse of person-first language is a cultural norm. ${ }^{22}$ 
Person-first language is more than a movement to minimize stigma toward individuals with disabilities. Studies have demonstrated that the language we use can impact the effectiveness of our care. ${ }^{23,24}$ Person-first language works against the one-size-fits-all framework, decreasing focus on the diagnosis and increasing focus on the person. ${ }^{22}$ This aligns with the principles of decision-making abilities posed by Grisso and Appelbaum. ${ }^{8}$ Person-first language promotes the appreciation of how diagnoses will affect an individual's self and unique situation. There is no such thing as a one-off perfect script for use across patients, such as individuals with Alzheimer's disease. Those who use such an approach to the informed consent process minimize person-centered care.

In order to effectively participate in an informed consent process, the SLP should be equipped with the relevant, current field knowledge regarding the decision to be made. A brief section lies here listing the current evidence for gastrostomy feeding tubes in the geriatric population.

To begin, this literature will always be limited to observational cohort studies at best. A randomized-controlled experiment in which some patients are randomized to receive a gastrostomy tube for artificial nutrition and hydration (ANH) and some patients who continue to eat by mouth is unlikely to be approved by an Institutional Review Board, given the inherent ethical dilemma. Consequently, it is no surprise that providers remain uneasy about this body of evidence and establishing cold, hard recommendations from it alone.

- In a review of the literature between the years 1991-1995 by Finucane \& Bynum, the use of enteral feeding tubes in patients with neurogenic dysphagia did not eliminate the risk of developing aspiration pneumonia. ${ }^{25}$ 
- Finucane, Christmas, \& Travis completed a review of the literature examining the outcomes of feeding tubes in patients with advanced dementia. Their search spanned the years 1966-1999. Their review determined that none of the literature at that point supported the use of gastrostomy feeding for the prevention of aspiration, prolonging survival, reducing the risk of pressure sores and infections, improving functional status (per the Functional Independence Measurement Scale), nor increasing a person’s comfort. $^{26}$

- Callahan and colleagues completed a prospective observational study examining the effects of functional status, cognitive ability, illness severity, comorbidity, and quality of life. In their cohort of 150 geriatric patients who received a gastrostomy tube, $50 \%$ died within one year. Of those who survived more than 60 days, $70 \%$ displayed no improvement in functional, nutritional, or subjective health. Importantly, this cohort included a range of diseases warranting ANH - stroke, neurodegenerative disease, cancer. There was no observable difference in outcomes between conditions. ${ }^{27}$

- Gillick urged a rethink of the use of feeding tubes in people with dementia and called for physicians to take the first step in educating the families that they work with. ${ }^{28}$

- In 2010 The Royal College of Physicians and British Society of Gastroenterology published a guide to oral feeding difficulties and dilemmas with a focus on practical care particularly towards the end of life. ${ }^{29}$

- An updated review by Goldberg \& Altman again determined that gastrostomy feeding did not improve long-term survival in patients with advanced dementia who underwent percutaneous endoscopic gastrostomy placement for dysphagia/elevated aspiration risk. ${ }^{30}$ 
- In 2014, The American Geriatrics Society published a formal position regarding the use of gastrostomy tube feeding in individuals with advanced dementia. Feeding-tube use was deemed associated with increased risk for agitation, use of physical/chemical restraints, tube-related complications, and development of new pressure ulcers. Careful hand feeding was judged to be at least as good as enteral feeding when it came to survival, aspiration pneumonia, functional status, and comfort. ${ }^{31}$

\section{Conclusions}

The SLP is a healthcare provider who, just like physicians, serves to promote the wellness of an individual patient while supporting that patient's right to manage her body as she sees fit. Speech-language pathology is a specialty field, and we will often find ourselves in challenging, “grey" situations. We are equipped with unique knowledge regarding our specialty and are bound by our Code of Ethics to participate in the informed consent process. A physician will ultimately determine a patient's clinical decision-making capacity, but our own fund of knowledge, patient assessments, dialogue with patients, and observations can certainly assist. SLPs can use the frameworks detailed regarding the functional abilities of a decision-maker and the requirements for truly informed consent to guide our practices away from defensive medicine and minimize our professional uncertainties. 


\section{References}

1. Miller RM, Groher ME. Speech-language pathology and dysphagia: A brief historical perspective. Dysphagia. 1993;8:180-184.

2. American Speech-Language-Hearing Association. 2017 health care survey summary report: Numbers and types of responses. 2017. www.asha.org.

3. American Speech-Language-Hearing Association. 2018 Schools survey. Survey summary report: Numbers and types of responses, SLPs, 2018. www.asha.org.

4. Colodny N. Dysphagic independent feeders' justifications for noncompliance with recommendations by a speech-language pathologist. American Journal of SpeechLanguage Pathology. 2005;14:61-70.

5. Jin J, Sklar GE, Oh, VMS, Li, AC. Factors affecting therapeutic compliance: A review from the patient's perspective. Therapeutics and Clinical Risk Management. 2008;4(1):269-286.

6. Grisso T, Appelbaum PS. Mentally ill and non-mentally-ill patients' abilities to understand informed consent disclosures for medication. Law and Human Behavior. $1991 ; 15(4), 377-388$.

7. American Speech-Language-Hearing Association. Code of Ethics [Ethics]. 2016. www.asha.org/policy.

8. Grisso T, Appelbaum PS. Assessing competence to consent to treatment: A guide for physicians and other health professionals. New York, NY: Oxford University Press; 1998. 
9. Horner J, Modayil M, Chapman LR, Dinh A. Consent, Refusal, and Waivers in PatientCentered Dysphagia Care: Using Law, Ethics, and Evidence to Guide Clinical Practice. American Journal of Speech-Language Pathology. 2016;25(4):453-469.

10. Sharp, H. M. \& Bryant, K. N. (2003). Ethics issues in dysphagia: When patients refuse assessment or treatment. Seminars in Speech and Language, 24(4), 285-299.

11. Karlawish J. Measuring decision-making capacity in cognitively impaired individuals. Neurosignals. 2008;16:91-98.

12. Mohr v. Williams, 104 N.W. 12 108. Minn 1905.

13. Schloendorff v. Society of New York Hospital, 105 N.E. 92. 211 NY 1251914.

14. Salgo v. Leland Stanford Jr University Board of Trustees, 317 P2d 170154 Cal App2d 5601957.

15. Canterbury v. Spence, 464 F.2d 772 (150 U.S.App.D.C. 263 1972).

16. Patient Self Determination Act, 42 U.S.C. § 1395cc (a) (1).1990.

17. Ryan M, Sinha. Informed procedural consent. UpToDate. 2017. https://www-uptodatecom.pitt.idm.oclc.org/contents/informed-proceduralconsent?topicRef $=98592 \&$ source $=$ see_link

18. Raab EL. The parameters of informed consent. Trans Am Ophthalmol Soc. 2004;102:225-232.

19. Grisso T, Appelbaum PS, Hill-Fotouhi C. The MacCAT-T: a clinical tool to assess patients' capacities to make treatment decisions. Psychiatr Serv. 1992;48(11):1415-1419.

20. Lai JM, Gill TM, Cooney LM, Bradley EH, Hawkins KA, Karlawish JH. Everyday decision-making ability in older persons with cognitive impairment. The American Journal of Geriatric Psychiatry. 2008;16(8):693-6. 
21. American Psychological Association. Guidelines for nonhandicapping language in APA journals: Committee on disability issues in psychology. 1992.

\section{https://www.apastyle.org/manual/related/nonhandicapping-language.}

22. Cocker A, Smith S. Person-first language: Are we practicing what we preach? Journal of Multidisciplinary Healthcare. 2019;12:125-129.

23. Heritage J, Robinson JD, Elliott MN, Beckett MB, Wilkes M. Reducing patients' unmet concerns in primary care: The difference one word can make. Journal of General Internal Medicine. 2007;22(10):1429-1433.

24. Storkenbeker IA, Houwan J, Lucassen PLBJ, et al. Quantifying positive communication: Doctor's language and patient anxiety in primary care consultations. Patient Education and Counseling. 2018;101:1577-1584.

25. Finucane T, Bynum JPW. Use of tube feeding to prevent aspiration pneumonia. The Lancet, 1996;348:1421-1424.

26. Finucane TE, Christmas C, Travis K. The feeding in patients with advanced dementia: A review of the evidence. JAMA. 1999;282:1365-1370.

27. Callahan CM, Haag KM, Weinberger M, et al. Outcomes of percutaneous endoscopic gastrostomy among older adults in a community setting. J Am Geriatr Soc. 2000;48:1048-1054.

28. Gillick MR. Rethinking the role of tube feeding in patients with advanced dementia. The New England Journal of Medicine. 2000;342(3):206-210.

29. Royal College of Physicians and British Society of Gastroenterology. Oral feeding difficulties and dilemmas: A Guide to Practical Care, Particularly towards the end of Life Clinical medicine (2010/04/23 ed.). London: Royal College of Physicians. 2010. 
30. Goldberg LS, Altman KW, The role of gastrostomy tube placement in advanced dementia with dysphagia: A critical review. Clinical Interventions in Aging. 2014;4(9):1733-1739.

31. American Geriatrics Society. Feeding tube in advanced dementia position statement. J Am Geriatr Soc. 2014;62:1590-1593.

Additional resources:

Mitchell SL. A 93year-old man with advanced dementia and eating problems. JAMA. 2007;298(21):2527-2536.

Morss DS. Enteral and parenteral nutrition in terminally ill cancer patients: A review of the literature. American Journal of Hospice \& Palliative Medicine. 2006;23(5):397-377.

Sampson EL, Candy B, Jones L. Enteral tube feeding for older people with advanced dementia. Cochrane Database Syst Rev. 2009;15(2). 


\section{CEU Questions}

An individual's competence, or legal capacity, is determined by:
a) a court of law
b) a police officer
c) a physician
d) a surrogate decision-maker
e) the patient himself

Which of the following are acknowledged as key functional abilities for making a clinical decision?
a) Ability to express a choice
b) Ability to understand the relevant information
c) Ability to appreciate the situation as it unique applies to oneself
d) Ability to reason through the options and consequences
e) All of the above

Decision-making capacity reflects a particular decision to be made:
a) at that distinct moment in time
b) for the duration of one week
c) for the duration of the illness
d) for the remainder of one's life 
The informed consent process must disclose:

a) Material facts

b) Provider disclosure

c) Personnel to be involved in the patient's care

d) Additional procedures that may be required

e) All of the above 